\title{
Annual Survey of Significant Developments in General Economic Theory
}

\section{J. Tinbergen}

Econometrica, Vol. 2, No. 1. (Jan., 1934), pp. 13-36.

Stable URL:

http://links.jstor.org/sici?sici=0012-9682\%28193401\%292\%3A1\%3C13\%3AASOSDI\%3E2.0.CO\%3B2-\%23

Econometrica is currently published by The Econometric Society.

Your use of the JSTOR archive indicates your acceptance of JSTOR's Terms and Conditions of Use, available at

http://www.jstor.org/about/terms.html. JSTOR's Terms and Conditions of Use provides, in part, that unless you have obtained prior permission, you may not download an entire issue of a journal or multiple copies of articles, and you may use content in the JSTOR archive only for your personal, non-commercial use.

Please contact the publisher regarding any further use of this work. Publisher contact information may be obtained at http://www.jstor.org/journals/econosoc.html.

Each copy of any part of a JSTOR transmission must contain the same copyright notice that appears on the screen or printed page of such transmission.

JSTOR is an independent not-for-profit organization dedicated to and preserving a digital archive of scholarly journals. For more information regarding JSTOR, please contact support@jstor.org. 


\section{ANNUAL SURVEY OF SIGNIFICANT DEVELOPMENTS IN GENERAL ECONOMIC THEORY}

\section{By J. Tinbergen}

ThIs survey may be opened with some apologetic remarks. The first is that to write a complete survey would mean to write a book. This has not been the intention of the editor, nor does it lie within the power of the present writer. Therefore, this survey is, in principle, incomplete, as will be easily seen by the many important authors whose work is not here discussed. The second remark is that a survey like this is, of necessity, one-sided and restricted. It is one-sided by reason of the special view of the writer on what is interesting and what is not; as, for example, this survey shows special interest in quantitative problems. It is restricted as a consequence of the fact that knowledge of nearly every individual about subjects more removed is less than about subjects in his direct neighborhood-both in a concrete and an abstract sense. The third remark relates to the subdivision of the material; it is difficult to represent, in a one-dimensional exposition, as the current text of a paper, a thing of multi-dimensional character.

First, we may consider the development of static theory in the last few years.

\section{STATIC THEORY}

In this field the Walrasian theory of market price may be taken as our starting point. This theory may be formulated in the following way: (1) To start with, it is assumed that a large number of subjects are present both on the "demand side" and on the "supply side" of the market. Each of these subjects realizes that he by himself will have little influence on price; he considers price as a given quantity. The only choice he can make consists in choosing the amount of money he will spend or the quantity of goods he will offer for sale per unit of time. (2) With the price given he will choose such an amount or quantity as will maximize his utility or ophelimity function, which is a given function of the quantities of different goods he buys or retains from production. (3) After this step the total amounts demanded and offered are confronted; the equilibrium price must be such as to equalize total demand and total offer, which means that we are confronted with the problem of the uniqueness of the solution.

Theoretical development in the last few years may appropriately be described by a separate consideration of each of these three elements in the argument.

The first point then is what we might call the organization principle of the market, culminating in the assumption that price is considered 
as a constant by each subject in the market. As was pointed out by many authors, this assumption is only plausible when the number of subjects is very large. Now in modern times there are numerous markets where only a few number of sellers or of buyers appear. The simplest case is that of a monopolist, and the theory of monopoly was developed in a brilliant way many years ago. The most difficult cases are, however, those called restricted competition or polypoly, where the number of sellers is small, but not "one." This case was considered particularly by Cournot, as early as 1838; later on, some discussion took place as to the validity of his solution, but in general little attention has been paid to this question. Especially in the last decade an intensive interest in these questions has developed, and the newer theoretical literature has made particular advances in this respect.

The difficulties in this problem arise from the fact that as soon as sellers ${ }^{1}$ are supposed to be able to influence prices, their ophelimity (or, more especially, their profit, to take a more realistic case) depends on quantity sold as well as on price. And this quantity is not, as in the case of monopoly, determined by price. Thus each seller seems to possess two "degrees of freedom," i.e., two independent ways of increasing his profits, and each way seems to lead to a "maximum condition." The number of equations, then, surpasses the number of variables, and no solution is to be found, in general. In other words, although each seller has, indeed, two ways to increase his profits, his action in certain respects hinders his colleagues, and is hindered by what his colleagues do; the question is in what way those interactions should be accounted for and in what way the case can be "styled" to get an appropriate picture of reality.

In Cournot's solution it was assumed that (1) each seller managed his quantity only, and (2) that he supposed the quantities offered by his colleagues not to change; further on it was assumed, in accordance with the Walrasian market, that (3) only one price exists at one time and that the total demand is determined by this price.

Those assumptions granted, Cournot's solution is, without doubt, the right one, as was pointed out anew by Wicksell and Schneider. ${ }^{2}$ Another question is, however, whether these assumptions are the only possible ones; what other hypotheses might be chosen; and which are fulfilled in each concrete case. Zeuthen showed that assumption (2) might be generalized, Hotelling gave alternatives as to (1), bringing

1 The argument may be used for buyers as well.

2 Wicksell, "Mathematische Nationalökonomie," Archiv für Sozialwissenschaft und Sozialpolitik, LviII (1927), 252; Amoroso, "La Curva Statica di Offerta," Giornale degli Economisti, xLv (1930), 1; and Schneider, Reine Theorie Monopolistischer Wirtschaftsformen (Tübingen, 1932), p. 132 seq. 
about changes in (2) and (3), and Chamberlin gave the more general view on the problem showing that there is indeed room for different assumptions. ${ }^{3}$ Zeuthen' ${ }^{4}$ contribution, given in a geometrical way, and generalized by Frisch, ${ }^{5}$ consisted in the treatment of several cases in which it was supposed that sellers take into account certain reactions of the other sellers for the case they themselves would change their variables.

Hotelling ${ }^{6}$ considered the case in which sellers manage prices instead of quantities. As soon as this is supposed, however, assumption (3) is impossible, and a refinement in this respect of the Walrasian market theory is the consequence: it must be assumed, in addition, that buyers have, in certain circumstances, reasons to buy at a higher price than is necessary. They must have a reason to choose, in certain circumstances, from two sellers asking different prices, the one with the higher price. Therefore, in addition to the above mentioned reactions of other sellers, there have to be considered reactions of buyers, the nature of which must also be given; the number of necessary data to solve the problem increases once more.

As a concrete example, Hotelling treats the case in which geographical distance causes some buyers to prefer a higher price to a lower one; adding that other similar causes, as personal sympathy or inertia, may be treated in an analogous way. His results are in many respects interesting and seem to offer wide perspectives for the introduction of geographical and similar elements into more complex problems. Considering two sellers and a distribution of buyers grouped with uniform density along one line, and assuming that transportation costs are proportional to distance, that production costs per unit are constant and equal, that demand is absolutely inelastic, and that both sellers fix their prices supposing the other to keep his constant, Hotelling reached the following conclusions: there will be a stable equilibrium with, in general, different prices for each of the sellers; these prices will equal production costs as soon as transportation costs vanish; when one of the sellers has to choose his "Standort" he will choose one as near to his competitor as possible; this choice is contradictory to the interest

${ }^{3}$ Cf. also Waffenschmidt, "Cournotsche Gleichungen für beschränkten Wettbewerb," Archiv für Sozialwissenschaft und Sozialpolitik, LXviI (1932), 513; and Sting, "Die polypolitische Preisbildung," Jahrbücher für Nationalökonomie und Statistik, cxxxIv (1931), 761.

4 Problems of Monopoly and Economic Warfare, London, 1930.

${ }^{5}$ At the Paris meeting of the Econometric Society, 1932, and in lectures at the Institut Poincaré, Paris, 1933. A brief account is published in the paper "Monopole-Polypole, La Notion de Force dans l'Êconomie Politique," Nationalфkonomisk Tidsskrift, 1933.

6 "Stability in Competition," Economic Journal, xxxix (1929), 41. 
of the community, as an unnecessary amount of transportation labor has to be done.

Chamberlin ${ }^{7}$ very clearly points out that there are two alternative possibilities as to the reactions of sellers upon the behavior of other sellers, none being a priori the "right" one or the "wrong" one. The two possibilities are indicated as "price adjustment" (with constancy of output) and "output adjustment" (with constancy of price). There might be room for mixed adjustment, as in Zeuthen's and Hotelling's case, or the general cases which Frisch calls "action paramétrique," but these possibilities are not considered by Chamberlin in full. $\mathrm{He}$ only treats one further case which represents a special case of Zeuthen's, the case, as he formulates it, in which sellers not only take into account the direct influence of their policy upon their colleagues, but also the indirect. The case Chamberlin considers consists in the extreme assumption that sellers foresee such reactions perfectly correctly and this leads to the result that equilibrium coincides with monopoly price and output (in a market with a uniform price) also when no open or tacit agreements exist. He then indicates certain causes counteracting this tendency and summarizes: "unless the number of sellers is very large, it would seem that the consumer can rely for protection against monopoly prices only upon (a) the sellers' lack of intelligence, or (b) their having only a temporary stake in the market, or (c) their uncertainty as to what their rivals will do. It is possible that these are adequate. At any rate, they are not the safeguards ordinarily contemplated by economic theory in explaining the price system."

It seems to me a real advance in our understanding of problems concerning markets with few sellers that we now realize that for a solution of those problems, there ought to be known more than the buyers' demand and the sellers' profit functions, and, in addition, that there may be several types of markets, or of sellers, according to the "reactions" above mentioned. It seems to be a further task for economists to determine the types to which real markets, or sellers, belong. It is possible, for instance, that in some markets sellers can only make price adjustments and no output adjustments. In retail trade for instance, where the ordinary "division of labor" between sellers and buyers may be formulated: sellers fix prices and buyers fix quantities. On the other hand, markets where other forms of contracts are customary, may belong to the type of "quantity adjustment markets." In very simple cases a statistical examination of the behavior of prices with the intention of finding out the type of market may be possible; in general,

7 "Duopoly: Value where Sellers are Few," Quarterly Journal of Economics, November 1929, p. 63. 
however, a large amount of data necessary for such investigations is still lacking.

In several cases treated by Zeuthen and Hotelling, there appear interesting problems, besides those relating to the exact place of the equilibrium point, concerning the question whether this equilibrium point will always be reached. As an example we may consider Cournot's original problem and its solution. This may appropriately be illustrated by the graphical representation given in Figure $1 .^{8}$ It is supposed there are two sellers only, the first selling the quantity $x_{1}$, the second $x_{2}$. Buyers are many and their aggregate demand function may be written as

$$
p=f\left(x_{1}+x_{2}\right) .
$$

Taking as coordinates $x_{1}$ and $x_{2}$, each point in our chart indicates one market position; $x_{1}$ and $x_{2}$ can be read off directly and $p$ is calculated
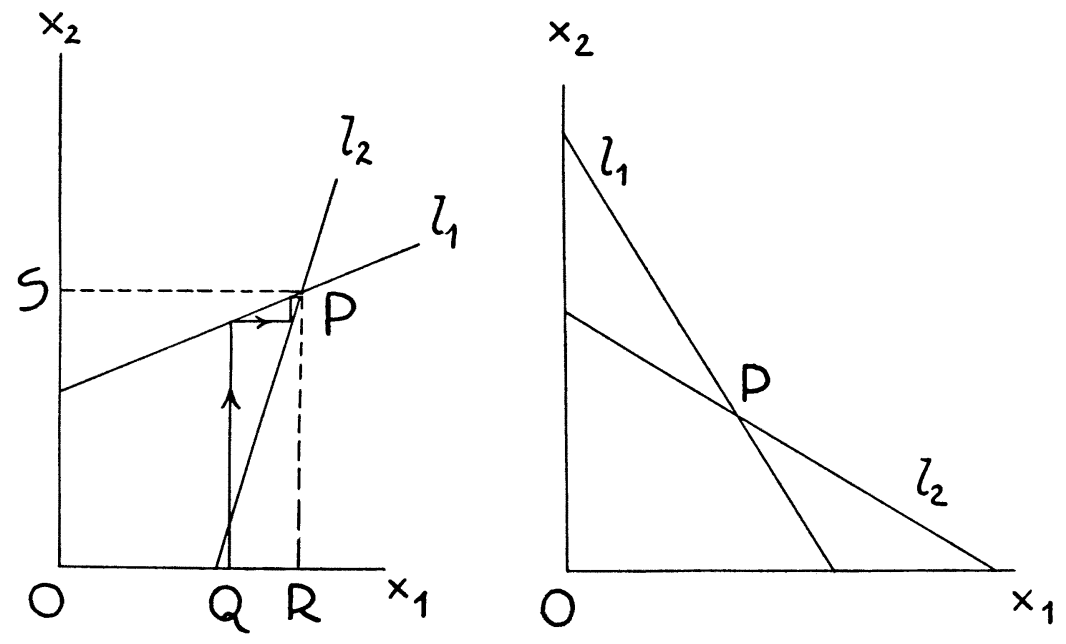

FIG. 1

with the help of (1). For each given $x_{2}$ it is possible to calculate the optimal $x_{1}$ for seller Number 1 ; the locus of these points is $l_{1}$; by analogy we have a locus $l_{2}$ for optimum situations for seller Number 2 when $x_{1}$ is given. The intersection point $P$ of $l_{1}$ and $l_{2}$ gives Cournot's equilibrium point; this may be demonstrated by studying the successive movements the sellers will carry out to improve their situationprovided that they suppose their competitor's output to be held con-

${ }^{8}$ Given for similar purposes by Hotelling, loc. cit., for the case where prices are independent variables. 
stant during each "act." The latter assumption-which is not, in its limited form, essential for our argument-means that each "act of improvement" undertaken by 1 consists in a vertical movement until $l_{1}$ is reached, and each "act of improvement" undertaken by 2 consists in a horizontal movement until $l_{2}$ is reached. Starting from a situation $Q$, e.g., such movements will lead to $P$ where they will stop, and in this respect $P$ is really the equilibrium point. This holds true for a large field of different starting points $Q$. Under certain conditions, however, it seems not to hold true for those $Q$ 's of which either $x_{1}$ or $x_{2}$ surpasses $P$ 's $x_{1}$ or $x_{2}$, i.e., for $Q$ 's outside the rectangle ORPS. To explain this, a certain mechanism of the "acts of improvement" must be postulated which seems, however, not unnatural. These acts may be looked at as consisting of two parts: (1) the active seller changes his price, and attracts thereby some new demand; (2) the passive seller follows with his price and herewith prevents "his" demand from being taken off. When the acts are "constructed" in this way, only such are possible where the price change is a price decrease; as the necessity for the competitor to follow does not exist in the case of a price increase. In our graphic representation this means that vertical movements from a higher to a lower point, as well as horizontal movements to the left, are excluded. As soon as the starting point is situated outside the rectangle, $P$ could not be reached. This statement has special importance for cases where (cf. the right side of Figure 1) $l_{1}$ and $l_{2}$ have a negative slope, as occurs in several important simple cases.

Up to this point we have discussed only problems related to a market where there is still a large number of competitors at one side. Problems grow still more difficult when at both sides a small number of competitors appears. Of those cases, only the case of monopoly at both sides has, as far as I know, been discussed rather thoroughly. I do not see, however, that much has been gained in this respect in the last few years. The most remarkable attempt to attack the difficulties seems to me to be Zeuthen's book, Problems of Monopoly and Economic Warfare (London, 1930), in which he tries to solve the problem in the special shape of the problem of collective bargaining. I must admit not to be sure to have understood the author's argument; it may be mentioned, however, as an original attempt, in which data are needed to solve the problem similar to the supplementary data we have found necessary to solve the problem of restricted competition at one side of the market.

Having discussed several problems relating to separate markets, we shall consider some questions that arise when a system of markets is studied. A first question in this field is that dealt with once more by Schneider in his book Reine Theorie monopolistischer Wirtschaftsfor- 
$m e n^{9}$; the question whether there exists, in a society in which all branches of production, including all factors of production, are monopolized, a state of equilibrium, and how it is to be determined. In this part of his book, Schneider develops a method which seems to have interesting features, although, in my opinion, he neglects to indicate the limits of its applicability. For each market considered he assumes that buyers accept - just as in the case of a unilateral monopoly - the price level as something they cannot influence, while sellers manage this price level in their own interest, i.e., in the way of the monopolist. Proceeding thus, it is possible indeed to solve this problem in an unambiguous way, and many of the criticisms on Edgeworth and Pareto added by the author seem legitimate. His assumptions on the structure of the considered markets will not hold, however, when the number of buyers is small, as may occur in different cases. Here either Cournot's mechanism or one of the other polypolistic theories must be applied-and these do not, so far as I can see, lead in all cases to a definite equilibrium point. To say it in a more popular way, a large trust that has a monopoly for its products, but, for instance, is itself one of three buyers for one of its materials, will certainly try to influence prices of this material and will, in all probability, not accept every price that is dictated.

Nevertheless, the method followed by Schneider seems to me to be very useful for further investigations in this field, a field that could be called the object par excellence of economics, as it compares different possible forms of organization of production. As far as I know, many interesting problems belonging to this object, and easily accessible to analysis, have not been treated yet, for example, the influence of vertical integration of horizontal trusts on prices of final products and total profits. The latter will, of course, increase, and hence one would expect prices to rise; but there are important cases in which this is not so and, on the contrary, prices fall.

Another interesting problem of interaction between markets is to be found in Von Stackelberg's Grundlagen einer reinen Kostentheorie (Vienna, 1932). Suppose two enterprises form a vertical amalgamation, and enterprise Number 1 supplies enterprise Number 2 with a certain commodity. Suppose, in addition, that each of the two enterprises has its own administration and price calculation, what then is the price which enterprise Number 1 should ask in order that the total profits of both enterprises are optimal?

Stackelberg's conclusion is that a distinction must be made between the case (1), where there is no market for the commodity in question,

๑ Tübingen, 1932; p. $83 \mathrm{ff}$. 
and (2), where there is a market. In the first case the price should be equal to production costs, in the second case it should equal market price-or may differ from that price by an amount, inversely proportional to the quantity bought by enterprise Number 2 .

Although of a quite different character, a problem of high practical importance suggested by Bauer, ${ }^{10}$ belongs to this class of problem, which might perhaps be called "problems in the structure of modern economic life." It is the divergency that arises in respect to the effects of rationalization between private and general interest as soon as a society is considered in which an unemployment dole exists. A private enterprise bases its decisions concerning rationalization on a calculation comparing (a) income and outlay in the existing situation with (b) probable income and outlay after a certain act of rationalization. It carries through this act of rationalization as soon as (b) shows a more favorable balance than (a). The interval in which this is the case does not coincide with the interval for which this rationalization is in the interest of the whole community. Apart from the question whether a simple calculation in terms of money is sufficient to point this out, the balance of the community shows one item in addition, the doles to be paid for those losing their occupation by the act of rationalization. As soon as these payments are included in the structure of the productive community this difference occurs, and there are reasons to assume that the difference is not unimportant.

Bauer also lays stress on other causes, for as he calls it "failing rationalization," e.g., a systematic error in the estimates for (b) because of a favorable business cycle phase, etc., but these have been recognized by earlier writers also (cf. p. 30, Theory of Risk). The interesting feature in the first-mentioned form of "failing rationalization" is its being connected with the new type of social measure that does not exist in the purer forms of capitalism. A further interesting question arises when the consequence is drawn from Bauer's argument that such failing rationalization should be prevented. This does not mean, as it would seem at first sight, a threatening of industrial progress, for the types of rationalization prevented would be only those giving a slight progress, while the more efficient types would be permitted. Moreover, a prevention of some forms of rationalization also seems useful in other respects. Suppose in a certain branch of industry five inventions occur, with time intervals shorter than half the life time of machinery used; then considering industry as a whole over the whole time interval, it will be more efficient to apply, e.g., inventions Numbers 1, 3, and 5,

${ }^{10}$ Kapitalismus und Sozialismus nach dem Kriege, I. "Rationalisierung-Fehlrationalisierung," Vienna, 1931. 
than to apply them all in succession, as soon as investments necessary at each new invention surpass a certain limit.

With these remarks our exposition of the "organization principle" of the market may be terminated; and the second step in the Walrasian market theory, i.e., the formation of demand and supply may be taken as a central point for further discussion of newer literature.

In the field of (static) demand and supply functions, most progress seems to have been made in statistical directions; it is not my task to deal with this subject here. In theoretical directions an important general tendency appears to be to make a distinction between the purely "psychical" demand and supply functions and the more "technical" ones. The distinction is not quite sharp, but the central thought is important. Psychical demand and supply functions are related immediately with psychical appreciation of the goods or services in question; the most important psychical demand is the demand by consumers for consumption goods; the most important psychical offer is the offer of labor and, in some circumstances, of capital. They form, so to say, the periphery of the economic system; the inner part of which has to deal only with "technical" demand and supply functions. The analysis of the latter requires a thorough knowledge of the technical structure of modern enterprise, and this field has constituted itself a more or less independent science. Many interesting problems dealt with in the last few years relate to this field, e.g., all questions connected with overhead cost, such as dumping, discriminating price policy, etc.

The principal general economic consequences of the intensified study of enterprise economics may be seen in the recognition that there are different types of supply and demand curves relating to the same enterprise, according to the number of production factors which are kept constant. ${ }^{11}$ This number not only depends on the estimated duration of price changes (the difference between long-run and short-run variations), but also on the intensity of such changes; a small change in output may be performed with a constant number of employees but with a varying number of laborers, whereas a larger change will be possible only by an increase in both categories. One has the impression, however, that a more general treatment of those problems has a limited significance; it will not be discussed here further.

Among the more remarkable contributions in the market-place aspect of demand and supply, two may be mentioned here. In the first

${ }^{11}$ Cf. e.g., Viner, "Cost Curves and Supply Curves," Zeitschrift für Nationalökonomie, III (1931), 23; Schneider, "Statische Kostengesetze," Nationalфkonomisk Tidsskrift, Lxx (1932) 393; Von Stackelberg, Grundlagen einer reinen Kostentheorie, Wien, 1932. 
place various publications by Ricci ${ }^{12}$ give a more elaborate classification of demand (or supply) curves into five or even seven groups, including different combinations of the elementary types: (1) elastic, (2) inelastic, (3) elastic-inelastic, (4) inelastic-elastic, (5) anelastic. Group (3) represents curves consisting of two successive parts, the first part being elastic, the second inelastic; group (5) is formed by curves whose elasticity is equal to one in all points. Further groups may be formedand are formed by the author-by considering curves whose elasticity changes twice, etc. In his expositions, Ricci operates with the notion of "(marginal) utility rectangles," being the product of abscissas and ordinates for each point of the curve, which is the same notion as Schneider's "marginal outlay" or "marginal receipts." It is clear that as the concept of elasticity can be applied to every curve these groups may be distinguished as well for other functions. The discussion between Frisch and Ricci concerning the group to which the utility curve for income belongs will be mentioned later on.

In the second place an attempt by Roy ${ }^{13}$ may be mentioned to show, with the help of a simplified example, in what way the distribution of income influences the aggregate demand for consumption goods. To fix the ideas, Roy assumes that commodities can be ranged according to their urgency, and that each individual first buys a constant quantity of commodity Number 1, or as much less as his income necessitates; of the residue, if any, he buys a constant quantity of commodity Number 2, as far as possible, etc. The influence of price on the quantity demanded is then to be ascribed to the fact that a definite price increment prevents a certain group of people from buying their "full" quantity. Although in most actual cases this seems not to be the only, and not even the most important reason for decreases of demand owing to price increases, Roy's case throws some light on the relations between division of incomes and slope of the demand curve.

A daring attempt in the last decade to make concrete the theory of marginal utility is that of Fisher ${ }^{14}$ and Frisch, the results of which have been published together in Frisch's New Methods of Measuring Marginal Utility. The statistical part of these investigations will not be discussed here; for our subject, however, the theoretical assumptions that form the starting point are very interesting. Frisch starts from the equation

${ }^{12}$ Cf. e.g., "Die Kurve des Geldnutzens und die Theorie des Sparens," Zeitschrift für Nationalökonomie, III (1932), 307.

13 "La demande dans ses rapports avec la répartition des revenus," Metron, 1930.

14 "A Statistical Method for Measuring Marginal Utility, etc." Economic Essays in Honor of John Bates Clark. 


$$
p=\frac{u}{v}
$$

in which $p$ means the price spent for a certain commodity, $u$ the marginal utility of that commodity to the buyer, and $v$ the marginal utility of money (or income) to that buyer. There will be very little difference of opinion among economists as to the validity of this equation; it is, practically speaking, generally accepted. The next step consists in the assumption that $u$ depends only on the quantity of the commodity in question consumed per unit of time by the subject in question, and that $v$ may be considered as a function of income. Granted this assumption, very interesting conclusions are possible by comparing two situations in which the individual (or family) is consuming equal quantities, but in which income and price are different, and differ in such a particular way that the quantity consumed of the special commodity of comparison (the reference commodity) is unchanged. By writing down the above equation for each of these situations and dividing the first by the second, we find, as the two $u$ 's are now equal:

$$
\frac{p_{1}}{p_{2}}=\frac{v_{2}}{v_{1}}=\frac{v\left(i_{2}\right)}{v\left(i_{1}\right)}
$$

That means that the quotient of the marginal utilities corresponding with the two income situations can be calculated from the two prices. After a correction for possible changes in the general index of cost of living, which we may not enter into now, it is possible to find in this way in what proportion the marginal utility of money falls off when income rises, figures that are of great interest for all sorts of social problems.

From a theoretical point of view, two questions are especially interesting, which I may only mention without giving a definite solution for them. The first is in what degree the assumption is admissible that $u$ depends only on the quantity consumed of this particular commodity. ${ }^{15}$ Everyone agrees that this does not hold for commodities having a substitute; the authors, however, exclude such commodities or think them combined; so the only question remains, are there really "independent" commodities? Is the increase of utility experienced with an increase in sugar consumption from $100 g$ to $200 g$ per week equal for a person who in other respects lives well and for one having no roof over his head? This example is, of course, an extreme one. As a first approximation, in cases which do not diverge so widely, it seems to me very

${ }^{15}$ At the University Institute of Economics, Oslo, work is actually going on to investigate this aspect of the problem.-EDITor. 
appropriate, however, to assume that there exist commodities (or services) that may be considered independent for the present purpose.

Another interesting question seems to me to be in what degree it is permitted to compare different individuals. By taking averages for large groups, individual differences may be eliminated. There is also the question of habit. Will a group having earned for a long time $\$ 2000$, and now earning $\$ 3000$, behave identically with a group always having earned $\$ 3000$ ? Again, as a first approximation, I consider the assumption of identity as appropriate, but the possibilities referred to must be borne in mind.

A controversy between Ricci ${ }^{16}$ and Frisch ${ }^{17}$ relating to change in money flexibility may be briefly mentioned here. It concerns the question as to which of the types of curves distinguished by Ricci (see above) the utility curve of money belongs. According to Frisch it is of the inelastic-elastic type, according to Ricci it is of the elastic-inelastic type. Frisch's opinion includes two properties of the curve:

1. The initial utility of income (i.e., the utility of the very first units of income) is infinite; and

2. No amount of income, however large, is sufficient to annihilate marginal utility of income.

These two statements are contested by Ricci. It will be very difficult, and somewhat cruel, to decide by experiment whether they are wrong or right! Of course, these questions only concern the results obtained by the statistical analysis. Frisch's method of measurement is quite independent of the above special form of the money utility curve.

We may now turn to the third step in static price and equilibrium theory: the equalization of supply and demand as one of the equations that determine price. In point of principle no objection can be made to this equation; at least in static theory. (In what respect it needs completion for dynamic problems will be considered further on.) It is a question, however, whether the solution of the equation for $p$ will always be possible without difficulties. There may indeed be difficulties; on one side the number of possible solutions may be great, on the other side there may be no solution. The first difficulty, that of plurality of roots, has been mentioned by many earlier economists; in the last few years it has been treated in some detail by Lorenz and Koopmans.

Lorenz, ${ }^{18}$ more in general, points to the large number of possible

${ }^{16}$ Cf. note 8.

${ }_{17}$ Zeitschrift für Nationalökonomie, II (1931), 625.

18 "Denkrichtüngen in der mathematischen Oekonomie und Statistik," Jahrbücher für Nationalökonomie und Statistik, cxxxvi (1932), 817. 
roots and to the wide range of uncertainty arising from the uncertainty in many of the data. Koopmans ${ }^{19}$ chooses some very much simplified examples in which only few subjects and few commodities play a rôle, the utility functions of these subjects in respect of these goods being quadratic - one of the simplest possibilities.

Another example of the difficulties that can present themselves in this field is signalized by Van Genechten ${ }^{20}$ who states that Böhm-Bawerk's theory does not yield any solution for the rate of interest when the productivity function (the function relating productivity to length of roundabout way) is increasing beyond a certain tempo. This holds good, as Van Genechten points out, as long as "simple interest" is calculated-as is done by von Böhm-but calculating with "compound interest" eliminates the difficulty.

A third example of the same type is provided by Keynes ${ }^{21}$ in his papers on the German transfer problem, when he points to the insolubility of the transfer problem-i.e., of the price problem for the German exchange rate - in one of two cases: (1) exports consist only of commodities of which output cannot be increased; or (2) exports consist only of articles having an elasticity of demand less than unity.

There are certain fields in general economics that are at present not so much in need of a broadening of the theoretical basis as in need of a minute working-out and concretization. Such problems present themselves in quite different divisions of economics. An example is given by a problem taken up by Engländer and studied in exact mathematical form by Frisch in a paper on a price theory with land and labor as factors of production. ${ }^{22}$ The main difficulties in this problem consist in the characterization of the different possibilities and their mutual limits. For instance: when price A lies between certain limits 1 and 2, and price $\mathrm{B}$ between limits 3 and 4 , product I will be chosen for production on a certain piece of land; when these prices lie between certain other limits, product II will be chosen, etc. These problems do not permit giving easily a summary of results; the survey can only mention them.

The same thing can be said of the newest development of those divisions of the theory of money, dealing with the velocity of circulation. Valuable work has been done by the more concrete estimations of that

19 "De mogelijkheid van meervoudig economisch evenwicht," De Economist, 1932, pp. 679, 766, and 841 .

${ }_{20}$ "Kritische Anmerkungen zur Zinstheorie," Zeitschrift für Nationalökonomie III (1932), 424, and Verminderende Meeropbrengsten (Haarlem, 1932), p. 163.

21 “The German Transfer Problem," Economic Journal, xxxix (1929), 1.

22 "Einige Punkte einer Preistheorie mit Boden und Arbeit als Produktionsfaktoren," Zeitschrift für Nationalökonomie, III (1931), 62. 
velocity by Keynes, ${ }^{23}$ Holtrop, ${ }^{24}$ Neisser ${ }^{25}$ and Marschak. ${ }^{26}$ Distinction is made by Neisser and, with certain variations, also by the other writers, between several "spheres": (a) the "sphere of income," (b) the "sphere of enterprises" or "business sphere"; (c) the financial circulation; (d) what is called by Neisser "organwirtschaftliche Zirkulation." The general velocity of circulation is a weighted average of the partial velocities in each of these spheres, and is to be corrected for irregular hoarding and extraordinary reserves. Very roughly speaking, the partial velocity of circulation in the income sphere (or, better, in the different sub-spheres of income groups) is determined by the "income period" - the time elapsing between two subsequent income payments. As to the business sphere two viewpoints exist, each of which may apply to certain sub-spheres of this sphere. The so-called amonetary viewpoint pays most attention to the effects of discontinuous sales or discontinuous expenses. In these circumstances the "quant character" (to use a physical term) determines the amount of money necessary for a given transaction per year and hence the velocity of circulation. On the other hand, the so-called monetary conception is more valid for continuous production; it considers the "degree of differentiation" and the "capital intensity" of production as the most important factors. By the "degree of differentiation" is meant the average number of changes of hands commodities undergo before they reach the last market, the market on which consumers buy. In connection with this notion a distinction is made between (1) "velocity of circulation," indicating the proportion between all payments made per annum for commodities and services in the income and the business sphere and the stock of money, and (2) "efficiency" of money, indicating the proportion between annual income and stock of money. It is difficult, however, to describe adequately the results of newer investigations in these fields because the most important contributions are those that give the most detailed analysis.

\section{DYNAMIC THEORY}

Let us turn now to dynamic problems. According to the definition

${ }^{23}$ A Treatise on Money. London, 1930.

${ }^{24}$ De omloopsnelheid van het geld, Amsterdam, 1928; German: Die Umlanfgeschwindigheit des Geldes, Beiträge zur Geldtheorie, herausgegeben F. A. von Hayek, Vienna, 1933.

${ }_{25}$ “Der Kreislauf des Geldes," Weltwirtschaftliches Archiv, xxxiII (1931), 365. "Volksvermögen und Kassenbedarf," Archiv für Sozialwissenschaft und Sozialpolitik, LXIX (1933), 484.

26 "Volksvermögen und Kassenbedarf," Archiv für Sozialwissenschaft und Sozialpolitik, LxviII (1933), 385. "Vom Grössensystem der Geldwirtschaft," Archiv für Sozialwissenschaft und Sozialpolitik, LXIX (1933), 492. 
of Frisch, ${ }^{27}$ the distinction between statics and dynamics is not a distinction between two sorts of phenomena, but a distinction between two sorts of theories, i.e., between two ways of thinking. The phenomena may be stationary or changing, the theory (the analysis) may be static or dynamic. According to Frisch, an analysis may be called dynamic if one or more of the relations on which it is built contain variables that belong to different instants of time. In other words, a given equation must contain at the same time magnitudes belonging to different instants. A special case of this is obviously an equation that contains at the same time a certain variable and the rate of change with respect to time of this variable. Frisch concludes: "Every law in which derivatives of variables with respect to time and those variables themselves appear, is a dynamic law-all other theoretical laws are static ones." I myself should prefer to include in dynamic laws also laws in which the connection with other instants is established in another way, for instance, by a simple time lag. ${ }^{28}$ In the following remarks I suppose such connections between different time points to be also dynamic.

As is pointed out also by Frisch and more tacitly by several others, the kind of problem is changed by introducing dynamic relations. In static problems the solution consists in the indication of certain values for each of the economic phenomena considered. In dynamic problems, however, it is not one value that must be determined, but a whole range of values, relating to every elementary time period considered. In mathematical language, all economic phenomena shall be determined as functions of time.

The simple fact that a series of successive situations is considered in dynamic analyses introduces into such analyses a number of new elements. Since the fundamental notion in each economic analysis is the ophelimity or utility function, we can formulate our present subject in this way: what new variables can appear in this function as a consequence of a dynamic treatment of the problem?

In statics, the variables appearing in the utility function are income quantities of all sorts of goods and services. Those income quantities

27 "Statikk og dynamikk i den okonomiske teori," Nationalфkonomisk Tidsskrift, LXVII (1929), 321.

${ }^{28}$ I quite agree to Tinbergen's formulation. The case of an equation connecting a variable and its rate of change with respect to time was intended as an example in the paper in Nationalфkonomisk Tidsskrift. I think this followed from the context, but I realize that the phrase quoted by Tinbergen may give rise to a misunderstanding. Later, in lectures at Yale and in Oslo (mimeographed), I have emphasized the fact that an equation connecting in any way whatsoever certain magnitudes that belong to different instants, may be looked upon as dynamic (or as cinematic, the difference between dynamics and cinematics is of no avail in the present connection).-EDitor. 
are not related to a certain time period, but are timeless. In dynamics the number of these variables is enlarged because, in principle, there may appear income quantities for each elementary time period in the future.

A first question of some interest is the question how many elementary time periods are represented in the utility function. In other words: for how long a period of time does the subject in question look forward? In newer literature this question has been mentioned several times without, however, leading to a systematic treatment. ${ }^{29}$ The notion itself has been used by many older economists, e.g., in the discussions on Böhm-Bawerk's theories, etc., but it seems that a more concrete use of it has only been made in later times, for example, in the investigations by Roos and Evans. ${ }^{30}$

Besides income quantities, in dynamic problems "stock quantities" may figure in the utility functions. It is especially by the systematic dynamic treatment of problems that the difference between "stock quantities" and "income quantities" is now recognized in a much clearer fashion than in the more static way of thought; the use of the word "stock" often has been ambiguous. Those authors using mathematics have the opportunity to make a very sharp distinction, as this distinction has a form very appropriate for mathematical treatment; a stock of commodity is to be considered as an integral over time of the difference between production and consumption per time unit. The newer statistical investigations into the price formation of important commodities have shown, in addition, that stocks often are simply related to prices; and a further concretization of the theory of price formation has been possible.

Among the variables appearing in dynamic utility functions there are many relating to the future. Of these some may, indeed, be known with certainty. Most of them, however, will not be known, and it is only the expectance of a certain amount that can be considered by the subject or that, unconsciously, influences his acts. Such expectancesprice as well as quantity expectances-play an important rôle in real phenomena, as was long since recognized. In the last few years, however, remarkable analyses have taken place in this respect.

Two problems, or complexes of problems, are especially interesting

${ }^{29}$ An attempt, not yet published, was made by Rosenstein-Rodan and discussed at the Lausanne meeting of the Econometric Society.

${ }^{30}$ Cf. e.g., C. F. Roos, "A Dynamical Theory of Economics," Journal of Political Economy, xxxv (1927), 637; “Dynamical Economics," Proceedings of the National Academy of Science, XIII (1927), 145; "A Dynamical Theory of Economic Equilibrium," ibidem, p. 280; G. C. Evans, Mathematical Introduction to Economics, 1930. 
in this field. First of all, the relation that exists between expectances for the future and actual facts. Second, the relation that exists between expectances about a certain phenomenon and the same phenomenon as it develops in reality. The first question asks on what data "forecasts" are based, the second, whether the forecast has been reliable. The difference between forecast and reality is a measure of the risk connected with certain acts depending on that forecast.

Statistical investigations in this field are, in many respects, difficult, as a number of the factors influencing expectances are never published and may be of a personal character. In the field of commodity as well as stock speculation, however, groups of data are available and have been collected that are appropriate to further investigations. Especially has a lot of material been collected by the United States Grain Futures Administration. It seems possible to interpret some of the regularities found with the help of simple assumptions, which form an appropriate example of the sort of analysis meant here. These simple assumptions relate to the trade in non-perishable crops. Assuming that dealers include in their calculations a distinct number of years, e.g., 2 or 3 , which we may call their horizon, and assuming further that their expectancy of future crops is, in accordance with the chance character of crops, that those shall be normal trend crops, it is possible ${ }^{31}$ to account for the facts (1) that there is a good correlation between loco and future prices except in years of marked shortage, (2) that the annual fluctuations in sales of such products are proportional but not equal to the corresponding fluctuations in "total available stock" at the beginning of each crop year, and (3) that there is an inverse correlation between price and "stock at end of crop year."

As a suggestive minor result, one finds a relation between horizon and the coefficient of proportionality between sales fluctuations and crop fluctuations. Although the assumptions from which one starts can undoubtedly only be looked upon as first approximations, the cases considered seem to be clear examples of phenomena not to be understood by static methods only. A wide field seems open, also, in slightly different directions, for successful investigations as to a more systematic knowledge of the fundamentals for expectances.

As to the other problem of expectances, it is generally recognized that there regularly appear differences between reality and what it had been expected reality would be. This divergence is a measure of the amount of risk connected with enterprise. The influence of risk on the formation of prices and income has been dealt with more systemati-

${ }^{31}$ Cf. my paper: "Ein Problem der Dynamik," Zeitschrift für Nationalökonomie, III (1932), 169. 
cally by e.g., Knight, ${ }^{32} \mathrm{Hardy},{ }^{33}$ and Hicks. ${ }^{34}$ It is, among other things, pointed out that although in a society in which risk exists a quasistatic equilibrium position may occur, there are systematic differences between such a state of things and an entirely static society, in which no risk occurs. New activities and new forms of income originate, and an absolute equilibrium no longer exists.

Another problem of great interest related to expectances, is the problem treated by Morgenstern ${ }^{35}$ : assuming business forecast is possible, what will be the influence on business cycles? In contradiction to many older writers on business cycle prevention, Morgenstern fears forecasts will tend to intensify rather than to smooth out cycles. For important cases, for instance when a further fall in prices is forecasted, this must be admitted without any doubt; there seems, however, to be need for further investigation of this problem, as cases may also be indicated in which forecasts have other results.

There are also other elements that play a rôle in the variation of dynamic utility functions. Time may be explicitly included in the utility function, for the same reasons demand and supply functions may depend explicitly on time. Many suggestions have been given concerning this theme by the statistical derivations of seasonal changes, many of which are good examples of this sort of time dependency.

The functional relation between a daily "income" of a certain commodity and the degree of utility experienced by the subject having this income, may be analysed more in detail when account is taken of the fact that the satisfaction of this subject varies during each consumption cycle. Just before the consumption act the intensity of the want, "the craving" will be high, it will drop during the consumption act, and between these acts it will increase gradually. These problems are considered in detail by Frisch in his paper on dynamics. ${ }^{36}$ In this study he arrives at the definition of marginal utility as a functional derivative, marginal utility itself being considered as a functional of the historical consumption curve. The most important part of this study is perhaps the distinction between what Frisch calls the "quenching curve" (the curve showing how the intensity of the want decreases during a rapid act of consumption), the "abstinence curve" (the curve showing the increase in intensity during a period where no consumption takes place), and the "maintenance curve" (the curve showing the connection between a given stationary level of consumption per unit

32 Risk, Uncertaity, and Profit, 1921.

${ }^{33}$ Risk and Risk Bearing.

34 "The Theory of Uncertainty and Profit," Economica (1931), p. 170

35 Wirtschaftsprognose, Vienna, 1928.

${ }^{36}$ Loc. cit., p. $349 \mathrm{ff}$. 
time and the corresponding stationary level of intensity). He shows that two of these three curves are empirically independent data, the third depending on the two others in a mathematically well-defined way. For instance, from the fact that marginal utility is decreasing in the quenching sense it does not follow that it is decreasing also in the maintenance sense. There may perhaps be difference of opinion as to whether these problems are economic or physiological ones.

In dynamics, as in statics, a market theory may be built up starting from the notions of utility, and either the Walrasian or the polypolistic sorts of markets may be considered. We will not deal with these questions in detail; we shall follow up certain aspects of the question only. An interesting field in this connection is the study of certain forms of technical conditions that are of a dynamic nature. These equations express the connections laid between variables at different instants by purely technical (or also institutional) circumstances. The simplest example is that of a constant time lag between the beginning and the end of a production process. This fact has been placed in the centre of interest by statistical investigations in relation to business cycles and with supply analysis of agricultural products. ${ }^{37}$ In many respects it seems to represent the simplest example of interrelations between two time periods. In a theoretical sense the problems related with such simple lags are interesting because they lead to oscillations in prices and production, some of which have been investigated statistically in a thoroughgoing way. A very interesting feature in the movements originating from the existence of lags is illustrated by Ricci. ${ }^{38}$ Supposing for a moment that both demand and supply are linear functions of price, but that there exists a certain lag between price and the corresponding supply, the price movement of the commodity in question, resulting from any initial disturbance of equilibrium, may have different shapes, illustrated by Figure 2. Starting with a price $\mathrm{OP}_{1}$, higher than equilibrium price, this price causes, after the given time lag, an offer of $\mathrm{P}_{1} \mathrm{P}_{2}$, to be found with the help of the supply curve $\mathrm{S}$. This offer can only be sold at a price $\mathrm{OP}_{4}$, to be found with the help of the demand curve D. After the time lag this gives a supply $\mathrm{P}_{4} \mathrm{P}_{5}$, etc. According to the quotient of the slopes of $D$ and $S$, we get (1) when D is steeper than S, damped oscillations; (2) when D and S have the same slope, strictly periodical oscillations; and (3) when D is flatter than S, still wider oscillations. When demand and supply curves are not straight lines but general curves, more complicated movements are possible.

${ }^{37}$ Bean, "The Farmers' Response to Price," Journal of Agricultural Economics (1929), p. 368; Hanau, Die Prognose der Schweinepreise, and many others.

38 "Die synthetische Ökonomie von Henry Ludwell Moore," Zeitschrift für Nationalökonomie, I (1930), 649. 
The main theoretical interest seems to lie, however, in the fact that rather insignificant changes in the slope of demand or supply curves can disturb the stability of a market. There are other cases of a more complicated nature, but in some respects more in accordance with the economic system as a whole, that show the same property. One example of a somewhat more complicated nature was dealt with by myself; it related to a market of durable goods, where things are somewhat different. Here a slight variation can alter an oscillating movement into a one-sided movement. Other examples are given by Goudriaan ${ }^{39}$ in connection with negatively sloped supply curves.
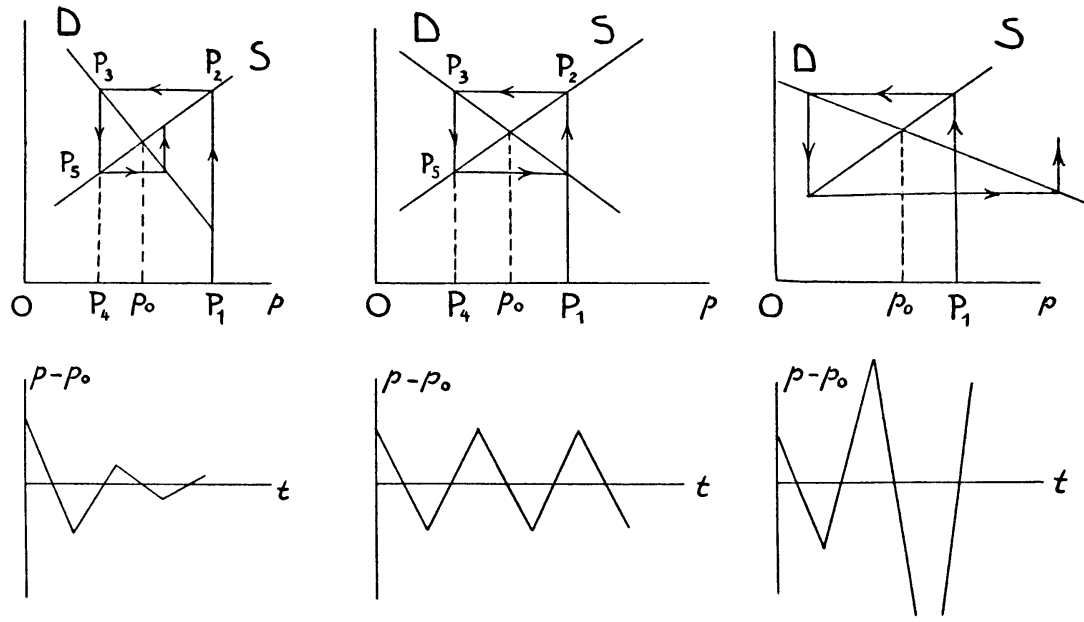

FIG. 2

Other examples of technical conditions binding variables of different time periods consist in the long lifetime of many means of production and some other commodities (furniture, clothing). This phenomenon introduces into the supply functions of such commodities integrals over longer periods giving an interesting mathematical feature to problems related to these markets. The same mathematical peculiarities appear when account is to be taken of the buying power of those involved in a production process lasting some finite time. This seems to have importance, especially in view of the newest development of business cycle theory and business cycle policy; but as this survey has to restrict itself to general economic theory, nothing will be said of those questions here.

A special case of a time lag is introduced when time is divided up into so-called "income periods," which are common now in the theory

${ }^{39}$ Cf. e.g., How to Stop Deflation, London, 1932. 
of money. Although these periods are, on the whole, short in comparison to the lags dealt with above, the influence of their existence is important. This is shown in a convincing manner by a recent paper by Koopmans on the problem of "neutral" money..$^{40}$ The central problem dealt with by Koopmans may be re-exposed here. It relates to the question whether "neutral money" is identical with "stable money." A neutral monetary system is characterized by the property that all prices and exchanged quantities of commodities and services behave as if the Walrasian conditions for equilibrium were fulfilled. In particular, income and outlay shall be equal at each moment, so that, in summa, no hoarding or creating of money is permitted. According to Koopmans, in a neutral monetary system, changes in the general price level are possible, whereas this is contested by other writers. To prove his statement he considers a society in which neutral monetary conditions are fulfilled and in which by a change in efficiency (or yield per acre for agricultural products) the price of one commodity A changes. Owing to the "doctrine of compensating price changes" other prices will move in the opposite direction and it will be possible to choose an adequate index of prices that will show no change. This doctrine is made plausible by its defenders by pointing to the buying power consumers of A will save (in the case of a fall of A-prices) or will be short of (in the case of a rise in A-prices).

On the other side there is a "doctrine of cumulative price changes" arguing that other prices will move in the same direction as A-prices; its adherents pay special attention to the buying power of those producing A.

A first interesting point in this controversy is, as Koopmans remarks, that results depend entirely on the assumption that the elasticity of demand for A is lower than 1. Suppose this elasticity to be higher than 1, and the results are quite the reverse! And the case of an elasticity equal to 1 is very appropriate to show that compensation is not necessary, for in that case no other price changes, and therefore the general index number of prices has to change in the same direction as A-prices. In principle this furnishes the proof that there is no form of index number for which in all cases neutral money is equivalent to stable money.

It is, however, interesting to follow Koopmans in his further expositions, as these will show us the influence of the time lag referred to.

Supposing that elasticity of demand for A be not equal to 1 , he states that the increase in buying power of A-producers is always com-

${ }^{40}$ Zum Problem des "neutralen" Geldes, Beiträge zur Geldtheorie, herausgegeben von F. A. Hayek, Vienna, 1933. 
pensated for by the decrease of buying power of A-consumers. (Increase as well as decrease may also be negative.) And so for those cases it is also easily proved that no other price changes occur. It is now interesting to confront this with the opinions of Stucken, Mahr, and Hawtrey, who deny the compensation just mentioned. Instead of that, they accept a sort of "law of compensating price sums," starting from the idea that money can be spent only once. The income earned in the last income period of the original status will be spent in the next period. When, then, A-prices have changed, and also A-quantities, the total sum spent on A will have changed, as soon as elasticity is either lower or higher than one. Suppose it has risen, then the total buying power available for other commodities will have decreased and their price level will fall. This means compensating movement when the change in A-price was a fall, and cumulative movement when this change was a rise.

This seeming contradiction arises from the fact that it has been supposed that in the first income period of the "new status" A only spends an income equal to that earned in the earlier periods. Had he been already spending in this first period an income corresponding to the new state of affairs, things would have taken their course as pointed out by Koopmans; and only the latter is in accordance with "neutral" money conditions. The picture given by the other writers may be far more realistic, Koopmans adds, but it is not a "neutral" situation. The lag appearing between A's earning of a certain income and spending it, is characteristic for a non-neutral monetary system.

The importance of this exposition is particularly clear when we continue the argument for some further income periods. The second income period after the original state of things shows, indeed, a larger buying power of A coming on the market; but, in addition, the other producers have now a smaller buying power just compensating A's. Suppose the original buying power spent per unit of time by all producers to have been $K$; originally the price of A may have been $p_{1}$, the quantity produced and consumed $a_{1}$, after the change these quantities may be $p_{2}$ and $a_{2}$.

In the first income period after the change there is spent: by A-producers, $a_{1} p_{1}$; by others, $K-a_{1} p_{1}$; in total, $K$. From this buying power, however, now $a_{2} p_{2}$ (supposed $>a_{1} p_{1}$ ) is spent on $\mathrm{A}$, therefore $K-a_{2} p_{2}$ on other commodities.

In the second income period there will be spent by A-producers $a_{2} p_{2}$, and by others $K-a_{2} p_{2}$, total, $K$. From this, again $a_{2} p_{2}$ will be spent on $A$, the rest on the other products. So the situation remains different from the situation created with a neutral monetary system. 
In summary, under the régime of neutral money only the price of A changes, other prices remain constant, the velocity of circulation of money has increased; under the prevailing monetary régime other prices may have compensated for A's price movement, and, in that case, the velocity of circulation has remained constant-but, depending on the elasticity of demand for A, also cumulative price movements are possible with a corresponding change in velocity of circulation.

An interesting use, from the theoretical viewpoint, of the nature of lags is made by Hayek ${ }^{41}$ in his newest theory of business cycles. I will not discuss in general his theory here, as this belongs to the subject of another survey, but his leading idea has importance for other divisions of theory also. Hayek points to the effects of an increasing "roundabout way of production" in the sense of Böhm, caused, as Hayek assumes, by the rising difference between the "real" and the "money" rate of interest. These effects consist in a certain shortage of products during the transition period, in which-to state the case with some exaggeration-products from the earlier production process may be said already to be consumed, and that of the later not yet deliverable. Here we have a problem related essentially to varying lags.

Varying lags are also introduced when the influence of a phenomenon $A$ on another phenomenon $B$ is of a cumulative nature, as is suggested by Hamburger and Le Corbeiller, ${ }^{42}$ who advocate the application of the theory of relaxation oscillations in economics. A simple case may be stated here for illustration. The influence of employment on wages may be considered as a relation with a constant lag between those two phenomena (trend movements eliminated). It may, however, also be looked upon as the consequences of a direct relation between employment and the velocity of movement of wages; and for a psychological interpretation it may be more natural to start from this latter relation. The effect of such a relation is, however, that wages are now lagging in a more irregular way after employment, as soon as employment itself shows deviations from a sine curve or from an exponential curve.

In newer literature some problems of a semi-theoretical character have been treated which, both as concerns the method used and their great practical importance, deserve attention. I mean the sort of prob-

${ }^{41}$ Hayek, Preise und Produktion, Veröffentlichungen des Oesterreichischen Instituts für Konjunkturforschung, Vienna, 1931.

42 "Een nieuwe weg voor conjunctuuronderzoek, een nieuwe richtlijn voor conjunctuurpolitiek," De Economist, Lxxıx (1930), 1; also: "Analogie des fluctuations économiques et des oscillations de relaxation," Indices du Mouvement des Affaires, Ix (1931), Supplement. 
lem dealt with, e.g., by Kahn..$^{43}$ The question is: given a situation of unemployment, the unemployed receiving a "dole," what will be the effect of supplementary investments (e.g. in the form of "public works" by governments) on unemployment? Kahn distinguishes three sorts of laborers coming into work again: (1) those employed in the public works, (2) those producing materials, machinery, etc., to be used in the public works, and (3) those employed because the first two groups expand their consumption by an amount, the value of which corresponds to the difference between wages and dole; those getting employed in the same way because of the group just mentioned having got work, etc. This last group is estimated by Kahn in a first approximation by the following argument. Let the difference between wages and dole be $k$ times the cost associated with the supplementary employment of one laborer; $k$ will be less than unity. Then, those mentioned first in the third group-getting their job by groups 1 and 2will be $k$ times groups 1 and 2 ; those mentioned in the second place in group 3 will be $k^{2}$ times groups 1 and 2 , and so on. In total group 3 will contain

$$
k+k^{2}+k^{3} \cdots=\frac{k}{1-k}
$$

times groups 1 and 2. Kahn estimates, with the help of data that we need not repeat here, that $\frac{k}{1-k}$ may be between 0.5 and 1 ; which is a very important result for practical purposes. It is not difficult to criticize this very simple method-also the author is aware of the approximate character of the whole method-it is far from easy, however, to indicate the limits of this approximation. As the author observes, the length of the income period (in the sense used formerly) is neglected; this is one of the reasons why the formula would give far too great values in the case that, for instance, the dole was zero.

\section{Rotterdam School of Economics}

43 "The Relation of Home Investment to Unemployment," Economic Journal, XLI (1931), 173. 
http://www.jstor.org

\title{
LINKED CITATIONS
}

\author{
- Page 1 of 2 -
}

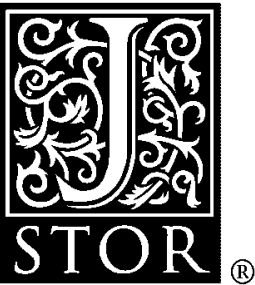

You have printed the following article:

\author{
Annual Survey of Significant Developments in General Economic Theory \\ J. Tinbergen \\ Econometrica, Vol. 2, No. 1. (Jan., 1934), pp. 13-36. \\ Stable URL: \\ http://links.jstor.org/sici?sici=0012-9682\%28193401\%292\%3A1\%3C13\%3AASOSDI\%3E2.0.CO\%3B2-\%23
}

This article references the following linked citations. If you are trying to access articles from an off-campus location, you may be required to first logon via your library web site to access JSTOR. Please visit your library's website or contact a librarian to learn about options for remote access to JSTOR.

\section{[Footnotes]}

\author{
${ }^{6}$ Stability in Competition \\ Harold Hotelling \\ The Economic Journal, Vol. 39, No. 153. (Mar., 1929), pp. 41-57. \\ Stable URL: \\ http://links.jstor.org/sici?sici=0013-0133\%28192903\%2939\%3A153\%3C41\%3ASIC\%3E2.0.CO\%3B2-F
}

\section{${ }^{7}$ Duopoly: Value Where Sellers are Few}

E. H. C.

The Quarterly Journal of Economics, Vol. 44, No. 1. (Nov., 1929), pp. 63-100.

Stable URL:

http://links.jstor.org/sici?sici=0033-5533\%28192911\%2944\%3A1\%3C63\%3ADVWSAF\%3E2.0.CO\%3B2-5

\author{
${ }^{21}$ The German Transfer Problem \\ J. M. Keynes \\ The Economic Journal, Vol. 39, No. 153. (Mar., 1929), pp. 1-7. \\ Stable URL: \\ http://links.jstor.org/sici?sici=0013-0133\%28192903\%2939\%3A153\%3C1\%3ATGTP\%3E2.0.CO\%3B2-H
}

\author{
${ }^{30}$ A Dynamical Theory of Economics \\ C. F. Roos \\ The Journal of Political Economy, Vol. 35, No. 5. (Oct., 1927), pp. 632-656. \\ Stable URL: \\ http://links.jstor.org/sici?sici=0022-3808\%28192710\%2935\%3A5\%3C632\%3AADTOE\%3E2.0.CO\%3B2-F
}

NOTE: The reference numbering from the original has been maintained in this citation list. 
http://www.jstor.org

\title{
LINKED CITATIONS \\ - Page 2 of 2 -
}

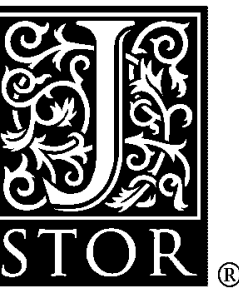

\footnotetext{
${ }^{30}$ Dynamical Economics

C. F. Roos

Proceedings of the National Academy of Sciences of the United States of America, Vol. 13, No. 3. (Mar. 15, 1927), pp. 145-150.

Stable URL:

http://links.jstor.org/sici?sici=0027-8424\%2819270315\%2913\%3A3\%3C145\%3ADE\%3E2.0.CO\%3B2-W
}

\author{
${ }^{30}$ A Dynamical Theory of Economics \\ C. F. Roos \\ The Journal of Political Economy, Vol. 35, No. 5. (Oct., 1927), pp. 632-656.
}

Stable URL:

http://links.jstor.org/sici?sici=0022-3808\%28192710\%2935\%3A5\%3C632\%3AADTOE\%3E2.0.CO\%3B2-F

\section{${ }^{34}$ The Theory of Uncertainty and Profit}

J. R. Hicks

Economica, No. 32. (May, 1931), pp. 170-189.

Stable URL:

http://links.jstor.org/sici?sici=0013-0427\%28193105\%291\%3A0\%3A32\%3C170\%3ATTOUAP\%3E2.0.CO\%3B2-8

\section{${ }^{43}$ The Relation of Home Investment to Unemployment \\ R. F. Kahn}

The Economic Journal, Vol. 41, No. 162. (Jun., 1931), pp. 173-198.

Stable URL:

http://links.jstor.org/sici?sici=0013-0133\%28193106\%2941\%3A162\%3C173\%3ATROHIT\%3E2.0.CO\%3B2-C

NOTE: The reference numbering from the original has been maintained in this citation list. 